\title{
Two genes differentially regulated in the cell cycle and by DNA-damaging agents encode alternative regulatory subunits of ribonucleotide reductase
}

\author{
Stephen J. Elledge ${ }^{1,3}$ and Ronald W. Davis ${ }^{2}$

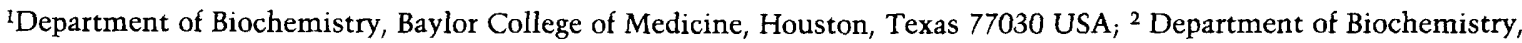 \\ Stanford University School of Medicine, Stanford, California 94305 USA
}

\begin{abstract}
Ribonucleotide reductase activity is essential for progression through the cell cycle, catalyzing the rate-limiting step for the production of deoxyribonucleotides needed for DNA synthesis. The enzymatic activity of the enzyme fluctuates in the cell cycle with an activity maximum in $\mathrm{S}$ phase. We have identified and characterized two Saccharomyces cerevisiae genes encoding the regulatory subunit of ribonucleotide reductase, $R N R 1$ and RNR3. They share $\sim 80 \%$ amino acid identity with each other and $60 \%$ with the mammalian homolog, $M 1$. Genetic disruption reveals that the RNR1 gene is essential for mitotic viability, whereas the RNR3 gene is not essential. A high-copy-number clone of RNR3 is able to suppress the lethality of mr1 mutations. Analysis of mRNA levels in cell-cycle-synchronized cultures reveals that the RNR1 mRNA is tightly cell-cycle regulated, fluctuating 15- to 30-fold, and is coordinately regulated with the POL1 mRNA, being expressed in the late $\mathrm{G}_{1}$ and $S$ phases of the cell cycle. Progression from the $\alpha$-factor-induced $G_{1}$ block to induction of $R N R 1$ mRNA is blocked by cycloheximide, further defining the requirement for protein synthesis in the $G_{1^{-}}$to $S$-phase transition. Both RNR1 and RNR3 transcripts are inducible by treatments that damage DNA, such as 4nitroquinoline-1-oxide and methylmethanesulfonate, or block DNA replication, such as hydroxyurea. RNR1 is inducible 3- to 5-fold, and $R N R 3$ is inducible $>100$-fold. When MATa cells are arrested in $G_{1}$ by $\alpha$-factor, $R N R 1$ and RNR3 mRNA is still inducible by DNA damage, indicating that the observed induction can occur outside of $S$ phase. Inhibition of ribonucleotide reductase activity by hydroxyurea treatment results in arrest of the cell cycle in $S$ phase as large budded, uninucleate cells. This specific cell-cycle arrest is independent of the RAD9 gene, defining a separate pathway for the coordination of DNA synthesis and cell-cycle progression.
\end{abstract}

[Key Words: Ribonucleotide reductase; DNA-damaging agents; DNA synthesis; cell-cycle progression]

Received December 19, 1989; revised version accepted February 12, 1990.

The eukaryotic cell cycle is a cascade of highly complex, sequential, independent, and interdependent events that culminate in the duplication of a cell. Many complex macromolecular structures must be assembled and disassembled with striking temporal and spatial precision. This degree of complexity necessitates the existence of a sophisticated regulatory network that is capable not only of coordinating these events but also of correcting mistakes that occur during these complex processes. One level of this organization is accomplished through the restriction of certain cell-cycle functions to particular periods of the cell cycle when they are needed. For example, DNA synthesis is restricted to a defined period of the cell cycle, S phase (Pringle and Hartwell 1981). This restriction is accomplished, at least in part, by the temporal modulation of the activity and expression of gene products needed specifically in S phase. In Saccha-

${ }^{3}$ Corresponding author. romyces cerevisiae, not only are genes encoding the enzymatic machinery for DNA synthesis cell-cycle regulated [for example $P O L 1$, DNA polymerase I (Johnston et al. 1987); $C D C 9$, DNA ligase (Barker et al. 1985; Peterson et al. 1985)], but so are many of the enzymatic activities involved in the production of the dNTP precursors needed for DNA synthesis [for example, $C D C 8$, thymidylate kinase (White et al. 1988); CDC21, thymidylate synthase (Storms et al. 1984) and ribonucleotide reductase (Lowden and Vitols 1973)]. Several other genes associated with DNA metabolism are also cell-cycle regulated; these include histones (Hereford et al. 1981), $H O$, an endonuclease involved in mating type switching; SW15, a regulator of mating type switching (Nasmyth 1987); and RAD6 (Kupiec and Simchen 1986). All of these genes are expressed in late $G_{1}$ and/or $S$ phase. In each case, with the exception of RAD6, which has not been tested, these genes are not expressed when cells are arrested in early $G_{1}$ by a cdc28 mutation or $\alpha$ - 
factor. $H O, C D C 8, C D C 9, C D C 21$, and POL1 are expressed immediately upon reaching the start of the cell cycle in late $\mathrm{G}_{1}$, before the $C D C 4$ block. The HTA1 and HTB1 genes are expressed in S phase after the CDC4 block. This regulation could occur at the level of mRNA synthesis or degradation, or both. In yeast, the only genes that have been examined so far, $H O$ (Nasmyth 1985), CDC21 (McIntosh et al. 1988), and HTA1 and HTB1 (Osley et al. 1986), are regulated at the level of mRNA synthesis, although post-transcriptional regulation is important for histone regulation in higher eukaryotic cells (Schumperli 1986). Positive- and negativeacting sequences are involved in cell-cycle regulation of the histone HTA1 and HTB1 genes (Osley et al. 1986), and mutations in the HIR genes have been identified that alter the negative regulation (Osley and Lycans 1987). hir mutations do not affect the regulation of the late $\mathrm{G}_{1}$ class of genes. The $H O$ gene encodes an endonuclease that is involved in mating type switching. It is under several other types of control in addition to cellcycle regulation and has an extremely complicated regulatory region. In the $H O$ promoter, a repeated sequence, $\mathrm{CACGA}_{4}$, has been found to confer cell-cycle regulation on a heterologous promoter (Nasmyth 1985). This repeat has not been found in any other cell-cycle-regulated genes. A DNA-binding factor has been identified that binds this sequence in a SW14- and SW16-dependent fashion (Andrews and Herskowitz 1989), but if and how that factor is cell-cycle-regulated is not known. The sequences regulating the remaining genes of the late $G_{1}$ class have not been identified.

As an initial approach to the problem of cell-cycle regulation, we chose to examine that of the enzyme ribonucleotide reductase. Ribonucleotide reductase catalyzes the first step in the pathway for the production of the deoxyribonucleotides needed for DNA synthesis. It is an enzyme of structure $\alpha_{2} \beta_{2}$. In yeast, the small subunit is encoded by RNR2 (Elledge and Davis 1987; Hurd et al. 1987). The activity of the enzyme fluctuates in the cell cycle with a maximum in S phase (Lowden and Vitols 1973). The amount of ribonucleotide reductase is also increased under conditions of nucleotide depletion (Lammers and Follman 1984). This increase in activity is likely due, in part, to increased transcription of the RNR2 gene, which has been studied extensively (Elledge and Davis 1989a,b; Hurd and Roberts 1989). It is induced in response to a wide variety of agents that either damage DNA directly through chemical modification or induce stress by blocking DNA synthesis. The induction of RNR2 mRNA can occur in $\mathrm{G}_{1}$ or $\mathrm{S}$ phase and is not blocked by the presence of cycloheximide. DNA from the promoter region of RNR2 can confer DNA damage inducibility upon a heterologous promoter. DNA damage inducibility is a feature common to several Sphase-specific genes $(P O L 1, C D C 8$, and $C D C 9)$ and may be connected to their cell-cycle regulation. To understand fully the regulation of ribonucleotide reductase in the cell cycle, we isolated the genes encoding the regulatory (large) subunit of the enzyme. This paper describes the isolation of these genes, their regulation in the cell cycle and by DNA-damaging agents, the phenotypes of mutations in these genes, and the effects of inhibition of ribonucleotide reductase on the cell cycle.

\section{Results}

Two genes, RNR1 and RNR3, encode alternate regulatory subunits of ribonucleotide reductase

Previous sequence analysis of the RNR2 gene encoding the small subunit of ribonucleotide reductase revealed that the yeast gene shared $60 \%$ sequence identity with its mammalian homolog (Elledge and Davis 1987). This suggested that if the genes encoding the large regulatory subunits were equally related, then the yeast gene could be isolated by using the previously cloned mouse gene as a probe (Caras et al. 1985; Thelander and Berg 1986). A $1.5-\mathrm{kb}$ BamHI fragment from the mouse large-subunit gene was used to probe a genomic library of yeast DNA in $\lambda$ at a reduced stringency, as described in Materials and methods. Two classes of cross-hybridizing $\lambda$ clones were obtained that differed in restriction maps (Fig. 1). The stringency-dependent degree of hybridization appeared to be the same for both classes of positives, suggesting that they shared an approximately equal percentage sequence identity with the mouse gene /data not shown). Furthermore, they each showed cross hybridization with probes derived from different regions of the
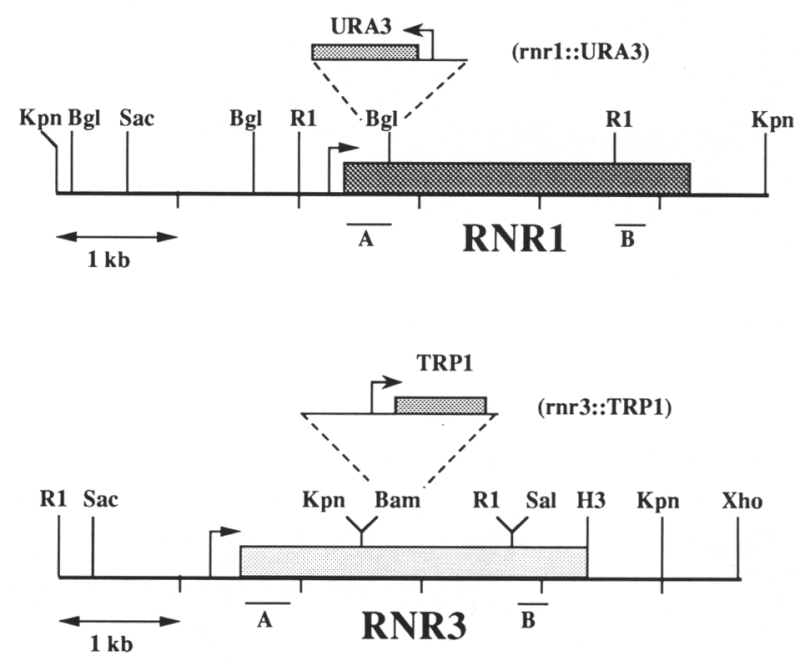

Figure 1. Restriction maps of the RNR 1 and $R N R 3$ genes. The solid lines represent chromosomal DNA. The shaded boxes represent the coding regions of the genes. The arrows indicate the direction of transcription. Restriction endonuclease cleavage sites are noted above the appropriate positions in the genes. Restriction enzyme sites are abbreviated as follows: (Bam) BamHI; (Bgl) BgIII; (R1) EcoRI; (H3) HindIII; (Kpn) KpnI; (Sac) SacI; (Sal) SalI; (Xho) XhoI. The URA3 and TRP1 genes shown above the $R N R$ genes show the sizes and positions of insertions used to create the chromosomal disruptions $\operatorname{mr} 1$ : URA3 and $r n r 3:: T R P 1$. $(A$ and $B)$ Regions of the RNR1 and RNR3 genes that have been sequenced in both strands. This information was used to derive the deduced amino acid sequence shown in Fig. 2. 
coding region of the mouse gene (data not shown), suggesting that the homology to the mouse gene was extensive.

Partial sequence analysis of the two genes revealed that they shared sequence identity throughout their lengths. The two yeast genes shared $\sim 80 \%$ sequence identity with each other and $\sim 60 \%$ identity to the mouse gene at both the nucleic acid and amino acid level (Fig. 2). The genes were named RNR1 and RNR3, respectively. RNA hybridization analysis determined that the RNR1 gene encoded a 3.2-kb mRNA, whereas no transcript was detectable for the $R N R 3$ gene (data not shown, see below).

The RNR1 gene is essential for mitotic viability and gives a CDC terminal phenotype upon disruption

To determine the phenotypes of mutations in RNR1 and $R N R 3$, disruptions of these genes were created in vitro by introduction of a selectable marker into the coding region of the two genes. These disruptions, $\operatorname{mr} 1::$ URA3 and $r n r 3::$ TRP1 (Fig. 1), were then introduced into the diploid yeast strain YNN402 by the method of transplacement (Rothstein 1983), selecting for Ura and Trp prototrophy, respectively. Disruptions were verified by Southern blot analysis. Two independently derived dip-

\section{A}

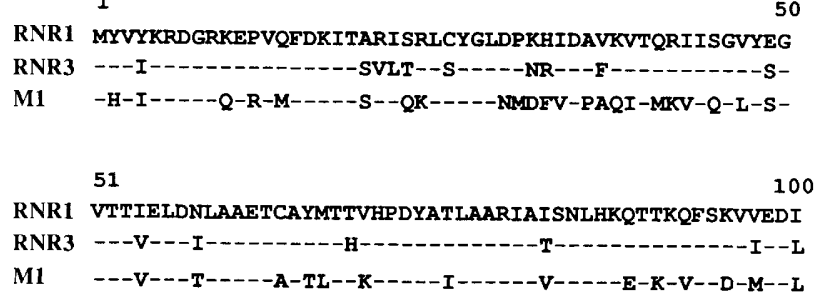

$\mathbf{B}$

1

RNR1 TGRFGIWDEGMKQYLLTENGSIQGLPNVPQQLKD . . . . . . .

RNR3 ---L----DS-----I-Q-------L--E--ELYKTSREISQKTIINM

M1 -E-A-I-NKE--NQIIAC-----SI-EI-DD--QLYKTVWEISQKTVIKM

\section{$51 \quad 63$ \\ RNR3 AADRAIYIDQSQS \\ M1 AAERGAFIDQSQS}

Figure 2. Comparison of the deduced amino acid sequence of portions of the mouse (M1) and yeast (RNR1 and RNR3) genes encoding the large subunit of ribonucleotide reductase. Dashes represent amino acid identities to the amino acid sequence of the RNR1 gene. Dots represent sequences that have not been determined. $|A|$ The deduced amino acid sequence of the amino-terminal region of the large subunits, including the start of translation, corresponding to the region labeled A in Fig. 1. $(B)$ The deduced amino acid sequence of an internal region of the large subunits corresponding to the region labeled $B$ in Fig. 1. loids heterozygous for respective $r n r$ mutations were allowed to undergo sporulation, and tetrad analysis was performed (Table 1). Of the 27 tetrads analyzed for the rnr1:: URA3 disruption, no tetrads with three or four viable spores were observed (Table 1). Twenty-five tetrads had two viable spores, and two tetrads had one viable spore, and all viable spores were Ura auxotrophs. Microscopic examination of the inviable spores revealed that they did germinate and undergo one or two rounds of cell division before arresting as large budded cells, a classical $C D C$ phenotype associated with mutations in genes involved in DNA synthesis.

Of the 32 tetrads analyzed for the rnr $3::$ TRP1 disruption, 29 had four viable spores and 3 had three viable spores (Table 1). The TRP1 gene segregated $2: 2$, indicating that the RNR3 gene is not essential for mitotic viability. The $\operatorname{rnr} 3::$ TRP1 haploids did not appear to have a growth defect relative to their $\mathrm{RNR}^{+}$sister spore clones.

\section{High-copy numbers of the RNR3 gene can suppress mutations in the RNR1 gene}

Although $R N R 1$ and $R N R 3$ share considerable sequence homology, rnr3 mutants had no observable phenotype and RNR3 message was not detectable in vegetatively growing cells. This suggested that the RNR3 gene may not encode a functional large subunit of ribonucleotide reductase. To search further for a function for $R N R 3$, the $R N R 3$ gene was placed on the TRP1-containing $2-\mu \mathrm{m}$ circle vector pRS46 to create pNN449 and tested to determine whether it could suppress a null mutation in RNR1. To facilitate this analysis, the sectoring shuffle assay developed by Elledge and Davis (1988) was employed. The RNR1 and SUP11 genes were placed on a centromeric vector, pUN95 (Elledge and Davis 1988), containing the HIS3 gene to create pNN448 and introduced into a haploid yeast strain YNN405 bearing an ade2 ochre mutation, producing YNN406. ade2 mutations cause the accumulation of a red pigment in strains grown under limiting adenine conditions. The presence of the SUP11 gene suppresses the ade2 mutation and prevents the formation of the red color. YNN406 colonies appear white when grown on limiting adenine medium lacking histidine but have red sectors when grown in the presence of histidine due to growth of cells that have lost the plasmid. Replacement of the chromosomal RNR1 gene in YNN406 with the rnr1: URA3 mutation resulted in homogeneously white colonies when grown on limiting adenine medium supplemented with histidine and uracil, indicating that loss of the plasmid RNR1 gene is lethal, as predicted by the tetrad analysis. Introduction of $\mathrm{pNN} 449$, which contains the RNR3 gene, into this strain restored the ability of the strain to grow in the absence of pNN448 and produced sectoring colonies. Southern analysis confirmed the genetic interpretation (Fig. 3); presence of a high-copy number of the RNR3 gene can suppress null mutations in RNR1, demonstrating that the RNR3 gene encodes a functional regulatory subunit of ribonucleotide reductase. 
Table 1. Tetrad analysis of RNR1 and RNR3 mutants

\begin{tabular}{|c|c|c|c|c|c|c|}
\hline \multirow[b]{2}{*}{ Strain } & \multirow{2}{*}{$\begin{array}{l}\text { Number of } \\
\text { viable spores } \\
\text { per tetrad }\end{array}$} & \multirow{2}{*}{$\begin{array}{l}\text { Number of } \\
\text { tetrads } \\
\text { observed }\end{array}$} & \multicolumn{4}{|c|}{ Genotype } \\
\hline & & & ura3 & $U R A 3$ & $\operatorname{trp1}$ & TRP1 \\
\hline \multirow[t]{4}{*}{ YNN403 } & 4 & 0 & 0 & 0 & & \\
\hline & 3 & 0 & 0 & 0 & & \\
\hline & 2 & 25 & 50 & 0 & & \\
\hline & 1 & 2 & 2 & 0 & & \\
\hline \multirow[t]{4}{*}{ YNN404 } & 4 & 29 & & & 58 & 58 \\
\hline & 3 & 3 & & & 5 & 4 \\
\hline & 2 & 0 & & & 0 & 0 \\
\hline & 1 & 0 & & & 0 & 0 \\
\hline
\end{tabular}

\section{RNR1 and RNR3 are both inducible by DNA damage}

Transcription of the RNR2 gene is inducible by a variety of treatments that damage DNA or block DNA synthesis. In addition, a number of other genes whose products are involved in DNA synthesis, such as $C D C 8$ (Elledge and Davis 1987), CDC9 (Barker et al. 1985), and POL1 (Johnston et al. 1987), are induced by DNA-damaging treatments. To examine whether the RNR1 and RNR3 genes share this mode of regulation, RNA was prepared from logarithmically growing cells with and without treatment with the DNA damaging agent 4-nitroquinoline-1-oxide (4-NQO). RNA hybridization analysis performed under stringent hybridization conditions showed that transcripts for both RNR1 and RNR3 were inducible by 4-NQO treatment (Fig. 4). Induction of the RNR1 transcript was $\sim 3$ - to 5 -fold, whereas the RNR3 transcript was inducible $>100$-fold. Analysis of densitometric tracings from greatly overexposed films has not allowed detection of a message from uninduced cells, suggesting that transcription of RNR3 is completely repressed in the absence of inducing treatments. The fact that $R N R 3$ is not normally expressed provides a simple explanation of why RNR3 mutants appear to have no growth defects.

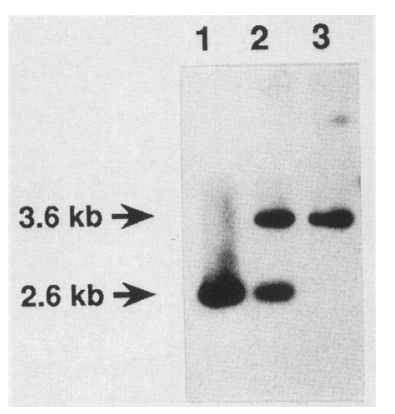

Figure 3. Demonstration of suppression of the $\operatorname{rnr} 1::$ URA3 mutation by high-copy number of the RNR3 gene through the use of the sectoring shuffle. Shown is a Southern blot analysis of DNA prepared from strains used in the sectoring shuffle. DNAs were digested with EcoRI, electrophoresed through a $1 \%$ agarose gel, transferred to nitrocellulose, and probed with the EcoRI-BgIII fragment of the RNR1 gene containing the start of translation. The sources of DNA are as follows: (Lane 1) YNN405; (lane 2) YNN407; (lane 3) YNN409.

\section{Transcription of RNR1 is tightly cell-cycle regulated}

The enzymatic activity of ribonucleotide reductase fluctuates in the cell cycle with an activity maximum in S phase in all eukaryotic cells that have been examined, including yeast (Lowden and Vitols 1973). In mammalian cells, this regulation is accomplished by modulating the levels of the small subunit, whereas the large subunit remains constant throughout the cell cycle (Engstrom et al. 1985). To determine whether modulation of transcript levels is involved in the cell-cycle regulation of ribonucleotide reductase activity in yeast, RNA was prepared from a yeast culture undergoing synchronous progression through the cell cycle. The yeast strain LN114 was arrested in $G_{1}$ by treatment with $\alpha$-factor. After $90-95 \%$ of the cells were arrested, the $\alpha$-factor was removed, and the cells proceeded synchronously through the cell cycle. Samples of cells were taken at 10-min intervals, and RNA was prepared and subjected to RNA blot analysis, with the RNR1, RNR2, POL1, and URA3 genes as probes (Fig. 5). The POL1 gene is cellcycle regulated and serves as an internal clock for timing the cell cycle and as a control for synchronization. The $U R A 3$ gene is not cell-cycle regulated and serves as a control for the amount of RNA loaded in each lane. The $R N R 1$ transcript is tightly cell-cycle regulated over several cycles and is coordinately expressed with the POL1 gene (Fig. 5), having an abundance maximum in S phase. The RNR2 transcript shows a weak, twofold fluctuation of levels relative to the $U R A 3$ transcript when analyzed by densitometer scanning of this and other RNA blots (data not shown). The fact that RNR1 message increases significantly in the first time point indicates that the factors controlling its abundance must sense a very early event after cells pass "start". These data suggest that the cell-cycle regulation of ribonucleotide reductase activity is likely to be due primarily to fluctuation in the levels of RNR1 message.

Progression from $G_{1}$ to RNR1 message induction requires protein synthesis

The pioneering work of Hereford and Hartwell demonstrated that progression of the cell cycle from $G_{1}$ to $S$ phase requires protein synthesis (Hereford and Hartwell 1974). The fact that mRNAs for several genes required 
for DNA synthesis, such as POL1, CDC8, CDC9, $C D C 21$, and $R N R 1$, are cell-cycle regulated provided a potential explanation for this observation, namely that these newly synthesized transcripts must be translated for DNA synthesis to be detected. Another possible explanation is that progression from $G_{1}$ to the induction of these transcripts, themselves, is dependent on protein synthesis. To test this hypothesis, cells were arrested in $G_{1}$ with $\alpha$-factor, incubated with cycloheximide, and then released from the $\alpha$-factor block while maintaining the presence of cycloheximide. RNA was prepared from these cells at various times after removal of the $\alpha$-factor, and RNA hybridization analysis was performed (Fig. 6). The control cells were not treated with cycloheximide and showed the anticipated fluctuation of RNR1 levels. However, the presence of cycloheximide completely prevented the accumulation of $R N R 1$ transcript. Similar results were obtained for the POL1 message /data not shown). These data demonstrate that the protein synthesis block to entry into $S$ phase occurs before induction of cell-cycle-regulated transcription or transcript accumulation.

Induction of RNR1 and RNR3 transcription by DNAdamaging agents is independent of the cell cycle

One explanation why ribonucleotide reductase and other genes whose activities are cell-cycle regulated respond to DNA damage is that they are needed outside of $S$ phase to produce a metabolic state that facilitates DNA synthesis needed for repair processes. That is, the DNA-damage sensory network provides a mechanism for heterochronic expression of these genes. This hypothesis would predict that $R N R$ induction occurs throughout the cell cycle. To test this hypothesis, the yeast strain RC634 was arrested in the $G_{1}$ phase of the cell cycle with the peptide hormone $\alpha$-factor (BuckingThrom et al. 1973). Arrested cells were then treated with the carcinogen methylmethanesulfonate (MMS), a methylating agent, and hydroxyurea (HU), a specific inhibitor of ribonucleotide reductase, as described in $\mathrm{Ma}$ terials and methods, while maintaining the presence of $\alpha$-factor. A population of asynchronous cells was used as a control. RNA was extracted from these samples after 4 $\mathrm{hr}$ of treatment with the inducing agents and size-fractionated, and the amount homologous to the RNR1, $R N R 3$, and URA3 genes was determined (Fig. 7). The message levels for both genes appear to increase relative to URA3 message levels in response to each inducing agent in both cycling and $\mathrm{G}_{1}$-arrested cells. Densitometer tracing of lighter exposures of URA3 reveals that lane 1 was underloaded by a factor of 2.3 relative to lane 4 . The RNR1 probe had a lower specific activity than the $R N R 3$ probe used in this experiment. Interestingly, induction levels for RNR3 message by HU and MMS were significantly lower in $\alpha$-factor-arrested cells than in the cycling population, whereas induction levels for RNR1 appeared slightly higher in $\alpha$-factor-arrested cells.

If $\mathrm{HU}$ generates a damage signal by stalling DNA replication through a depletion of dNTPs, it would be sur-

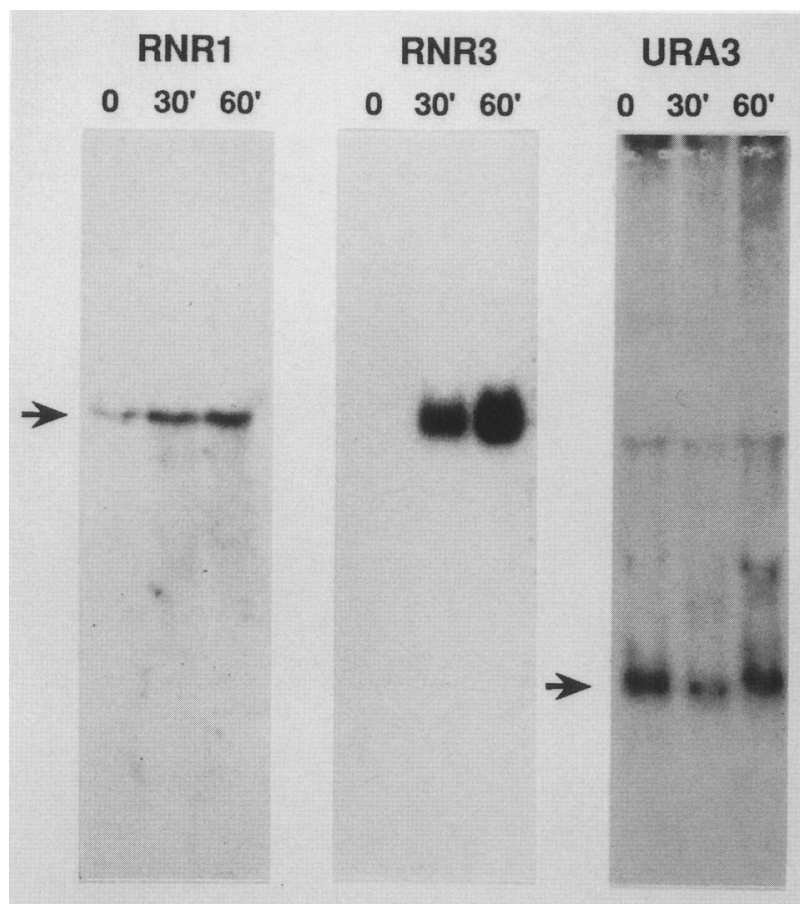

Figure 4. Northern blot analysis of the induction of $R N R 1$ and $R N R 3$ messages by 4-NQO. Individual cultures of $S$. cerevisiae SK46 were grown to an $\mathrm{OD}_{600}$ of 1.0 , and 4-NQO was added to a final concentration of $0.25 \mu \mathrm{g} / \mathrm{ml}$. Cultures were incubated with shaking at $30^{\circ} \mathrm{C}$ for 0,30 , and $60 \mathrm{~min}$, after which cells were harvested and RNA was prepared. The numbers above each lane indicate the length of time each sample was exposed to 4-NQO. The gene name (top) represents the probe used. Probes are described in Materials and methods.

prising to see induction in the absence of S-phase-dependent DNA replication. However, mitochondrial DNA replication proceeds in a cell-cycle-independent manner and may be responsible for the generation of a stress signal if nucleotide levels are not maintained in the presence of HU. It is also possible that nucleotide pools turn over at a significant rate in the absence of DNA replication and that nucleotide levels may play a role in the signaling. The fact that induction by HU was lower in $\mathrm{G}_{1}$-arrested cells for RNR3 suggests that an S-phase-dependent function, perhaps chromosomal DNA replication, may contribute to the stress signal produced by $\mathrm{HU}$, or perhaps the $R N R 3$ transcripts are less stable in $G_{1}$ than in the rest of the cell cycle. Clearly, these data show that DNA damage induction can occur outside of $S$ phase, supporting the heterochronicity hypothesis.

\section{Blocking DNA replication arrests the cell cycle through a RAD9-independent pathway}

Organisms show a specific arrest of the cell cycle at the $\mathrm{G}_{2}$-to-M transition in response to DNA damage (Burns 1956). In $S$. cerevisiae, this response pathway is controlled by the $R A D 9$ gene. rad 9 mutants are sensitive to killing by a number of DNA-damaging agents and fail to show the specific cell-cycle arrest in response to DNA 


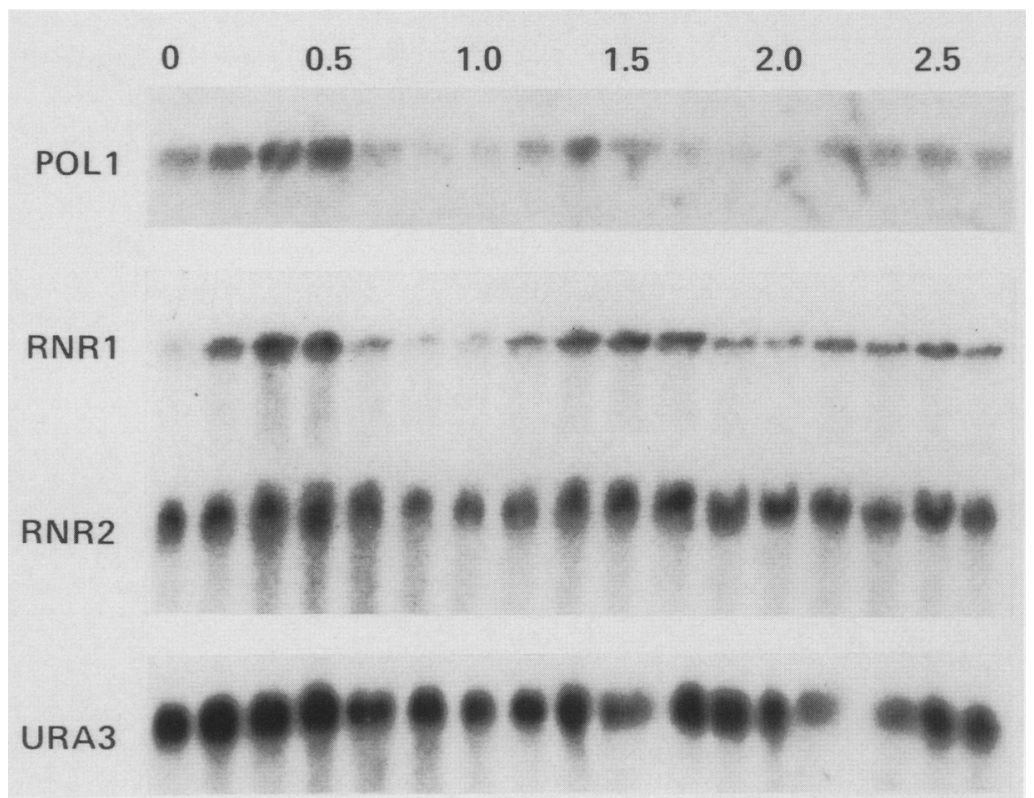

Figure 5. RNR1, RNR2, and POL1 levels in a culture of cells synchronized by $\alpha$-factor treatment. LN114 cells were grown to $\mathrm{OD}_{600}$ of 0.5 and synchronized in $G_{1}$ by $\alpha$-factor treatment, as described in Materials and methods. After cells accumulated in $\mathrm{G}_{1}, \alpha$-factor was removed and cells progressed synchronously through the cell cycle. Cells were harvested at 10-min intervals and RNA was prepared, fractionated on a formaldehyde/ $1 \%$ agarose gel, transferred to nitrocellulose, and probed. The numbers (top) represent the time after release from $\alpha$-factor. (Left) The gene name represents the probe used. Probes are described in Materials and methods. damage (Weinert and Hartwell 1988). rad9 mutants have an "anti- $C D C$ " phenotype with respect to several $C D C$ genes such as cdc2 and $c d c 9$ (Weinert and Hartwell 1989). RNR1 and RNR2 mutations arrest with the same terminal phenotype as $c d c 2$ mutant, singly budded, uninucleate cells. The specific inhibitor of ribonucleotide reductase, $\mathrm{HU}$, also arrests cells with the same $C D C$ phenotype (Slater 1973). Because HU treatment appears to be capable of activating the same stress response pathways that many DNA-damaging agents activate, it seemed possible that it may achieve its cell-cycle arrest via the $R A D$ 9-dependent pathway. To test this hypothesis, isogenic $\mathrm{Rad}^{+}$and rad 9 cells were treated with $\mathrm{HU}$, and the cell-cycle stage distribution of the cells was determined (Table 2). The presence of the rad 9 mutation had no effect on the cell-cycle arrest induced by HU treatment. These data demonstrate that inhibition of DNA synthesis causes a cell-cycle arrest that is independent of the RAD9 gene and thus further defines the cellular checkpoint responsible for coordinating DNA synthesis and mitosis. These data do not rule out the possibility that the HU treatment may be capable of activating the $R A D$ 9-dependent cell-cycle-arrest pathway.

\section{Discussion}

Two genes encode the regulatory subunit of ribonucleotide reductase in $\mathrm{S}$. cerevisiae

The regulatory subunit of ribonucleotide reductase has two sites for allosteric regulation of the enzymatic ac-

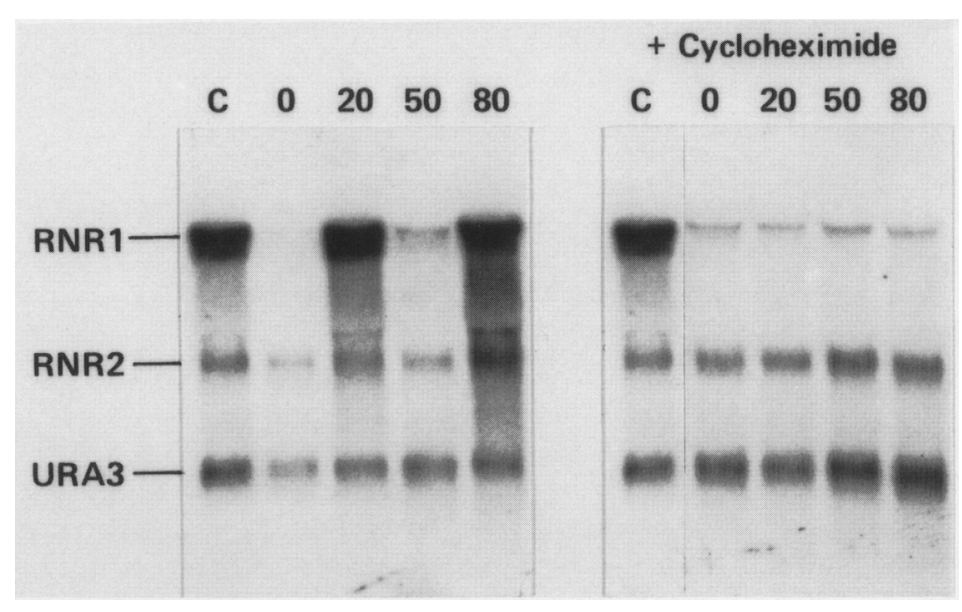

Figure 6. Progression from the $\mathrm{G}_{1}$-induced $\alpha$-factor block to expression of RNR1 is dependent on protein synthesis. LN1 14 cells were grown to $\mathrm{OD}_{600}$ of 0.5 and synchronized in $G_{1}$ by $\alpha$-factor treatment, as described in Materials and methods. The culture was split, and cycloheximide was added to one sample to a final concentration of 100 $\mu \mathrm{g} / \mathrm{ml}$. Cells were incubated with the drug for $10 \mathrm{~min}$, and the $\alpha$-factor was removed while maintaining the presence of cycloheximide. The other sample was handled identically but was never treated with cycloheximide. Cells were harvested at 0-, 20-, 50-, and 80-min intervals, and RNA was prepared, fractionated on a formaldehyde/ $1 \%$ agarose gel, transferred to nitrocellulose, and probed. The numbers (top) represent the time in minutes after release from $\alpha$-factor. (C) RNA from cycling ceils that were not treated with $\alpha$-factor. (Right) With the exception of C, lanes are from cells treated with cycloheximide. Treatment of cycling cells with cycloheximide alone does not reduce the RNR1 message (data not shown). The gene name at left of each band represents the gene encoding that transcript. Probes are described in Materials and methods. A higher degree of synchrony was obtained in this experiment than in the experiment shown in Fig. 5. 


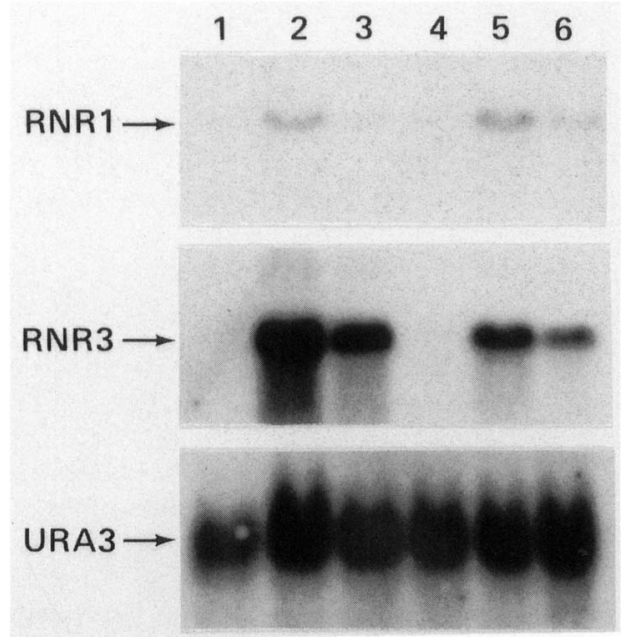

Figure 7. Induction of the RNR 1 and $R N R 3 \mathrm{mRNA}$ by $\mathrm{HU}$ and MMS in growing cells and during $G_{1}$ arrest by $\alpha$-factor. RNA was extracted from untreated RC634 cells (lane 1), $100 \mathrm{~mm}$ HU-treated cells (lane 2), 0.01\% MMS-treated cells (lane 3), and from $\alpha$-factor-arrested RC634 cells with no damage treatment (lane 4), arrested cells treated with $100 \mathrm{mM}$ HU (lane 5), and arrested cells treated with $0.01 \%$ MMS (lane 6). Northern blots of these RNAs were hybridized with ${ }^{32} \mathrm{P}$-labeled RNR1-, RNR3-, and URA3-specific probes, as described in Materials and methods, and the transcripts were visualized by autoradiography. Lane 1 was underloaded by a factor of 2.3 relative to lane 4.

tivity. One site is responsible for balancing the nucleotide pools by altering the substrate specificity of the enzyme in response to nucleotide concentrations, and the second allosteric site is involved in feedback regulation, measuring the dATP/ATP ratio and modulating the overall activity of the enzyme. Two genes, RNR1, and $R N R 3$, encode the regulatory subunit of ribonucleotide reductase in $S$. cerevisiae. Under normal vegetative conditions, only the RNR1 gene is expressed, and thus the ribonucleotide reductase in the cell is of a homogeneous form, $\alpha l_{2} \beta_{2}$. However, in the presence of DNA damage, the second large subunit gene is induced, producing at least one $\alpha 2_{2} \beta_{2}$ and possibly two $\alpha 1 \alpha 2 \beta_{2}$ additional forms of ribonucleotide reductase differing in their subunit composition. The physiological role of RNR3 remains to be determined. The yeast strains mutant for $R N R 3$ have no obvious growth defects and are not sensitive to $\mathrm{HU}$ or DNA-damaging agents (S.J. Elledge and R.W. Davis, unpubl.). Furthermore, the yeast strain that lacks $R N R 1$ and overproduces $R N R 3$ is not sensitive to HU (S.J. Elledge and R.W. Davis, unpubl.), suggesting that the RNR3 protein can substitute efficiently for the RNR1 protein when overproduced. The term "overproduced" is used loosely here because expression levels of the protein have not been measured. What, then, is the role of RNR3? Clearly, it must confer some selective advantage for the cell to have conserved both its function and tight regulation. One possibility is that it has altered regulatory properties, allowing the cell to survive certain types of stress that have yet to be duplicated in the labo- ratory. For example, biological fungicides are rampant in the wild and are often targeted to inhibit key regulatory enzymes. Perhaps, the evolutionary history of $S$. cerevisiae included growth in an ecosystem in which inhibitors of ribonucleotide reductase were a commonly employed competitive strategy. Duplication of the target gene would facilitate the rapid evolution of drug-resistant variants. Alternatively, the RNR3 gene may play a role in a nonvegetative function of yeast such as meiosis. The true role remains to be determined.

\section{Ribonucleotide reductase is cell-cycle regulated at the level of mRNA accumulation}

Both the RNR1 and RNR2 transcripts appear to fluctuate through the cell cycle. The RNR1 message is tightly cell-cycle regulated, with levels fluctuating 15- to 30 fold in experiments achieving a high degree of synchrony, whereas the RNR2 message showed a modest 2 -fold fluctuation. The RNR1 message is reduced to very low levels in $G_{1}$ in contrast to the RNR2 transcript. This difference may be a reflection of differing message stabilities for the two genes; RNR1 mRNA must have a very short half-life to undergo this striking modulation of levels. Likewise, to observe fluctuation of enzymatic activity, at least one of the subunits of ribonucleotide reductase must have a short halflife. The regulation of the yeast genes is in contrast to the cell-cycle regulation of the mammalian enzyme in which transcription of the small subunit $(M 2)$ is modulated, whereas the transcript for the large subunit (M1) remains relatively constant. However, Ml is transcriptionally regulated, being repressed upon entry into $\mathrm{G}_{0}$ during serum starvation (Mann et al. 1988). It is not clear whether the apparent cell-cycle regulation of RNR1 is mechanistically related to the serum starvation response of mammalian cells. Analysis of how other eukaryotes differentially regulate this gene pair will provide an interesting study in the evolution of eukaryotic gene regulation.

This transcriptional regulation is likely to account for the cell-cycle regulation of the enzymatic activity but does not rule out contributing post-transcriptional mod-

Table 2. Cell cycle arrest of S. cerevisiae by $H U$ is independent of RAD9

\begin{tabular}{|c|c|c|c|c|}
\hline \multirow{2}{*}{$\begin{array}{l}\text { Cell-cycle } \\
\text { stage }\end{array}$} & \multicolumn{2}{|c|}{$\begin{array}{c}\mathrm{YNN} 410 \\
\left(\mathrm{RAD}^{+}\right) \text {cells } \\
(\%)\end{array}$} & \multicolumn{2}{|c|}{$\begin{array}{c}\text { YNN411 } \\
\left(\operatorname{rad9}:: \begin{array}{l}U R A 3) \text { cells } \\
(\%)\end{array}\right.\end{array}$} \\
\hline & $-\mathrm{HU}$ & $+\mathrm{HU}$ & $\overline{-\mathrm{HU}}$ & $+\mathrm{HU}$ \\
\hline Unbudded & 22 & 2 & 24 & 1 \\
\hline Small buds & 27 & 1 & 28 & 1 \\
\hline Large buds & 51 & 97 & 48 & 98 \\
\hline
\end{tabular}

Cell cultures grown to mid-log phase in YPD were split, and half of each culture was made $200 \mathrm{mM}$ HU. Cultures were then incubated for $4 \mathrm{hr}$ at $30^{\circ} \mathrm{C}$ with shaking, at which time cultures were assayed for their distribution in the cell cycle by light microscopy. Small budded cells were defined such that the daughter bud was $<25 \%$ of the size of the parent cell. 
ifications. T lymphocytes are arrested in the $G_{1}$ phase of the cell cycle by exposure to cAMP. Albert and Nodzenski (1989) have shown that mammalian small subunit M2 is phosphorylated by a cAMP-dependent protein kinase and that this phosphorylation decreases the activity of the enzyme. They suggest that this modification may play a role in the cell-cycle arrest caused by cAMP. It is not yet known whether the yeast proteins are also kinase substrates or whether their stabilities are modulated in the cell cycle.

The $R N R 1$ transcript is coordinately regulated with that of the POL1 gene within the resolution of these experiments, being induced in late $G_{1}$ directly after cells pass "start". This coordinate expression is appropriate because both functions are needed at the same time to promote DNA synthesis. This message accumulation could be due to modulation of the rate of transcription or modulation of message stability. Both mechanisms function to promote cell-cycle message accumulation in mammals. Although these genes are similarly regulated, it is not clear whether they share precisely the same regulation. Further experiments are needed to answer this question. Nevertheless, the early induction of these genes suggests that the cis-acting sequences responsible for their regulation must be sensing a very early event or events in the commitment to enter the cell cycle and will serve as tools to probe these early events.

\section{Progression from the $\alpha$-factor block to induction of RNR1 requires protein synthesis}

The ability to induce the RNR 1 and POL1 messages after arrest in $G_{1}$ is dependent on protein synthesis. This may explain the early observations of Hereford and Hartwell that progression from the $\alpha$-factor-induced $G_{1}$ arrest to $S$ phase required protein synthesis. Although further analysis is required to determine whether this is a general requirement of all $G_{1}$-arrested states or is specific to the $\alpha$-factor arrest, it does raise some interesting possibilities. One possibility is that a new message transcribed immediately upon passing "start" must be translated to activate transcription of these genes. If this is true, a differential cDNA screen looking for transcripts expressed after the $\alpha$-factor block but before the cycloheximide block should identify the gene of interest. Another interesting possibility is that a critical level of a protein product must accumulate for progression into $S$ and activation of transcription and that the mechanism by which $\alpha$-factor arrests the cell cycle is by specifically depleting or altering this protein. Cycloheximide would then act to block the accumulation of that protein after release from the $\alpha$-factor block. The best candidate for such a protein is cyclin. Cyclins were identified because of their unusual behavior during the cell cycle (Evans et al. 1983). Cyclins accumulate during the cell cycle, peaking in abundance at the end of $G_{2}$. After cells enter mitosis, the cyclins are rapidly destroyed. Cyclins are thought to be involved in the activation of the kinase activity of p34, a protein kinase highly homologous to the CDC28 protein of $S$. cerevisiae. CDC28 regulates entry into $\mathrm{S}$ phase in $S$. cerevi- siae, and three cyclin homologs have been identified that appear to be involved in this regulatory step: WHI1, also known as DAF1 (Cross 1988; Nash et al. 1988), CLN1, and CLN2 (Hadwiger et al. 1989). WHI1 has been implicated in the $\alpha$-factor-arrest pathway /Cross 1988; Courchesne et al. 1989). Depletion or physical alteration of cyclins could occur during $\alpha$-factor arrest, thereby blocking the activation of CDC28 causing cell-cycle arrest. Recovery would then be mediated by the cycloheximide-sensitive synthesis of new, unaltered cyclins.

RNR1 and RNR3 transcripts are inducible by agents that damage DNA or block DNA replication

Although many cell-cycle-regulated activities are required primarily in one stage of the cell cycle, circumstances can arise when these activities are needed outside of the period when they are normally expressed. Consequently, multiple types of regulation are often interwoven into the control of cell-cycle-regulated genes. The RNR1 and RNR3 genes join a large group of genes with cell-cycle-regulated activities involved in DNA synthesis that are inducible by agents that damage DNA or block DNA replication. The induction of these genes in response to the stress of DNA damage is thought to produce a metabolic state that facilitates DNA replicational repair processes (Elledge and Davis 1987; Elledge and Davis 1989a). The fact that the common function shared by these genes is their role in DNA synthesis suggests that the cellular response regulating their expression is designed to promote efficient DNA synthesis. The ability of cells to synthesize DNA is high during $S$ phase, and it is likely that the additional induced levels of these enzymes produced by DNA damage would not significantly alter the repair capacity of the cell in that stage. However, outside of S phase, the levels of these activities drop, and with them the capacity to synthesize DNA. The ability of this DNA damage sensory pathway to induce heterochronically the capacity to synthesize DNA outside of $S$ phase is likely to be the major selective advantage to the cell. The overall objective of the cell-cycle regulation and the DNA-damage regulation is the same, to provide the capacity to synthesize DNA when it is needed. Therefore, these different regulatory pathways may share common components. Perhaps, the DNA damage sensory network activates gene expression via the existing cellcycle regulatory circuit. This important possibility remains to be explored.

Ruby and Szostack (1985) identified a number of genes, DIN (damage inducible), whose levels of expression increase in response to DNA-damage treatments. One such gene, DIN1, was recently sequenced and found to be identical to RNR3 (K. Yagle and K. McEntee, pers. comm.).

Cell-cycle arrest by inhibition of ribonucleotide reductase defines a RAD9-independent checkpoint for regulation of the cell cycle

Among the responses to the stress of DNA damage 
shared among organisms is a specific arrest of the cell cycle at the $\mathrm{G}_{2}$-to-M transition (Burns 1956). This response is thought to allow cells additional time to process and repair DNA damage prior to chromosome segregation, thus avoiding potential mitotic catastrophes associated with attempting to process incompletely repaired and replicated chromosomes. In $S$. cerevisiae, this response pathway is controlled by the RAD9 gene. rad9 mutants are sensitive to killing by a number of DNA-damaging agents and fail to show the specific cellcycle arrest in response to DNA damage /Weinert and Hartwell 1988). Furthermore, rad9 mutants have an anti-CDC phenotype with respect to several $C D C$ genes such as $c d c 2$ and $c d c 9$ (Weinert and Hartwell 1989). RNR1 and RNR2 mutations, as well as the specific inhibitor of ribonucleotide reductase $\mathrm{HU}$, arrest cells with the same terminal phenotype as cdc2 mutants, singly budded, uninucleate cells. HU-induced cell-cycle arrest, however, is not dependent on the RAD9 gene. This result formally differentiates these two cell-cycle arrest pathways for yeast. Although the RAD9 gene appears to coordinate some aspects of DNA metabolism and cellcycle progression, it cannot be responsible for the primary sensing of DNA replication progression because rad9 null mutations have no striking mitotic phenotypes in the absence of DNA damage. The HU-induced arrest pathway is more likely to be that involved in the coordination of DNA synthesis and mitosis. If this is true, we would predict that any agent arresting the yeast cell cycle with $C D C$ phenotype by blocking DNA replication would also arrest in a RAD9-independent manner, via this $S$ phase coordination checkpoint. In support of this, Schiestl et al. (1989) have found that $C D C 8$ retains its $C D C$ phenotype in a rad9 background.

Ribonucleotide reductase plays a central role in the eukaryotic cell, being responsible for both producing and balancing the deoxynucleotide pools needed for DNA synthesis. Mutations in it have been linked to a variety of phenotypes, including increased spontaneous mutation rates, loss of mitochondrial function, and DNA repair deficiencies. Ribonucleotide reductase is regulated by the cell cycle and is, itself, an indirect regulator of the cell cycle; progression from $G_{1}$ to $S$ is needed to activate ribonucleotide reductase expression, and active ribonucleotide reductase is needed to progress from $S$ to $G_{2}$. In addition to sensing cell-cycle positional information, it is capable of sensing the structural integrity of the DNA itself, being induced in response to DNA damage or blocks in DNA replication. The central themes of this work, cell-cycle progression, cell-cycle-regulated gene expression, and DNA-damage responsive gene expression, can all be approached through the study of the $R N R$ genes encoding ribonucleotide reductase.

\section{Materials and methods}

\section{Media and chemicals}

Yeast minimal medium contains $0.67 \%$ yeast nitrogen base without amino acids (Difco Laboratories, Detroit, MI); $2 \%$ glucose and $2 \%$ Bacto-Agar (Difco) are added for solid media. Se- lective medium used is minimal medium supplemented with various amino acids and bases, as prepared by Sherman et al. (1979), as was YPD media. MMS was purchased from Eastman Kodak Co. (Rochester, NY), and yeast $\alpha$-factor, 4-NQO, and HU were purchased from Sigma Chemical Co. (St. Louis, MO). Restriction enzymes, T4 polymerase, and DNA ligase were purchased from New England Biolabs and used under the conditions suggested by the supplier.

\section{Isolation of the RNR1 and RNR3 genes using low-stringency hybridization}

A $\lambda$ EMBL3A library of yeast genomic DNA was probed at reduced stringency with a ${ }^{32}$-labeled 3.0-kb BamHI fragment of the mouse $\mathrm{Ml}$ cDNA as a probe. Filters were prepared by the method of Benton and Davis (1977) and hybridized to denatured probe $\left(10^{6} \mathrm{cpm} / \mathrm{ml}\right)$ in $5 \times \mathrm{SSPE}, 0.1 \%$ SDS, $5 \times$ Denhart's solution, and $100 \mu \mathrm{g} / \mathrm{ml}$ denatured salmon sperm DNA at $42^{\circ} \mathrm{C}$ overnight without formamide. Filters were washed twice with 1 liter of $5 \times$ SSPE and $0.1 \%$ SDS at $42^{\circ} \mathrm{C}$ and exposed to film while wet. This was repeated at $52^{\circ} \mathrm{C}$ and $62^{\circ} \mathrm{C}$, taking special care not to let the filters dry out. Ten plaques that retained signal at the $62^{\circ} \mathrm{C}$ wash were purified for further analysis. DNA was prepared from these phage, and Southern analysis was performed to determine that each phage contained DNA that would cross-hybridize with the M1 probe. Phage fell into two classes that were based on restriction maps as described in the text.

\section{DNA sequencing}

Plasmid DNAs were sequenced by the method of Sanger et al. (1977). Single-stranded plasmid DNAs were prepared by the method of Zagursky and Berman (1984), by use of R408 (Russel et al. 1986) as a helper phage.

\section{Strains and plasmids}

Yeast strains used in these experiments are presented in Table 3 . The E. coli strain used as a host for constructions and plasmid amplification was JM107. pRS46 is a $2-\mu \mathrm{m}$-based TRP1 vector provided by $R$. Sikorfki and J. Shero. p215 is a clone of the chromosomal SUP11 locus, and p330 is a clone of the chromosomal TRP1 gene, both provided by P. Hieter (unpubl.). The pUN vectors were described previously (Elledge and Davis 1988).

\section{Plasmids constructed for this study}

The RNR1 and RNR3 genes were subcloned from their respective phage clones, and these subclones were used as sources of DNA for all subsequent manipulations. The RNR1 gene was subcloned as a 5.9-kb KpnI fragment into KpnI-cleaved pUN10 to create pSE738. The RNR3 gene was subcloned as a SacIXhol fragment into Sacl-Xhol-cleaved pBS KS+ (Stratagene, San Diego, CA) to create pSE734. Plasmids containing the gene disruptions were made in the following way. A $2.6-\mathrm{kb}$ EcoRI fragment from pSE738 containing the translational start of $R N R 1$ was subcloned into the $E c o \mathrm{RI}$ site of $\mathrm{pBS} \mathrm{KS}{ }^{+}$to create pSE736. A BgIII-BamHI fragment containing the URA3 gene was ligated into $B g / I I$-cleaved pSE736 to create pNN446, a $U R A 3$ disruption of the RNR1 gene. A BgIII fragment containing the TRP1 gene from p330 was cloned into the BamHI site in pSE734 to create pNN447, a TRP1 disruption of the $R N R 3$ gene. pNN448 was created by a triple ligation between the 1.0-kb EcoRI-KpnI SUP11-containing fragment of $\mathrm{p} 215$, the 
Table 3. Strains and plasmids used in this study

\begin{tabular}{|c|c|c|}
\hline Strain & \multicolumn{2}{|l|}{ Genotype } \\
\hline YNN402 & \multicolumn{2}{|c|}{ MATa/MAT $\alpha$ ura3-52/ura3-52 LEU2/leu2-3,-112 ADE2/ade2-101 } \\
\hline YNN403 & \multicolumn{2}{|c|}{ YNN402 RNR1/rnr1 :: URA3 } \\
\hline YNN404 & \multicolumn{2}{|c|}{ YNN402 RNR3/rnr3 :: TRP1 } \\
\hline YNN405 & \multicolumn{2}{|c|}{ MATa ura3-52 $\Delta$ his3-200 $\Delta$ trp1-800 ade2-101 lys2-901 } \\
\hline YNN406 & \multicolumn{2}{|c|}{ YNN405 pNN448 (RNR1 HIS3) } \\
\hline YNN407 & \multicolumn{2}{|l|}{ YNN406 rnr1 :: URA3 } \\
\hline YNN408 & \multicolumn{2}{|c|}{ YNN407 pNN449 (RNR3 TRP1) } \\
\hline YNN409 & \multicolumn{2}{|c|}{ YNN405 rnr1 $:: U R A 3$ pNN449 (RNR3 TRP1) } \\
\hline YNN410 & \multicolumn{2}{|c|}{ MATa ura3-52 $\Delta$ his3-200 trp1-289 ade2-101 leu2-3,-112 } \\
\hline YNN411 & \multicolumn{2}{|c|}{ YNN410 rad9 $::$ URA3 } \\
\hline RC634 & \multicolumn{2}{|c|}{ MATa sst $1-3$ rme1 ade2 his 6 met1 ura1 can1 cyh2 } \\
\hline LN114 & \multicolumn{2}{|c|}{ MATa ura3-52 $\Delta$ his3-200 trp1-289 ade2-101 } \\
\hline SX46 & \multicolumn{2}{|c|}{ MATa ura3-52 his3-832 trp1-289 ade2-101 } \\
\hline Plasmid & Relevant markers & Base plasmid \\
\hline pNN446 & $\operatorname{rnr} 1:: U R A 3$ & pBS KS ${ }^{+}$ \\
\hline pNN447 & $\operatorname{mr} 3:: T R P 1$ & $\mathrm{pBS} \mathrm{KS}^{+}$ \\
\hline pNN448 & RNR1 SUP11 HIS3 CEN4 ARS1 & pUN95 \\
\hline pNN449 & $R N R 3$ TRP1 $2 \mu \mathrm{m}$ & pRS46 \\
\hline
\end{tabular}

5.3-kb SacI-KpnI RNR1 fragment from pSE738, and the EcoRISacI-cleaved pUN95 (HIS3 CEN4 ARS1) (Elledge and Davis 1988). pNN449 was made by cloning a SacI(blunt)-XhoI RNR3containing fragment from pSE734 into KpnI(blunt)-SalI sites of pRS46. The SacI and KpnI sites were made flush by treatment with T4 DNA polymerase.

\section{Yeast strains constructed in this study}

The diploids heterozygous for the RNR1 and RNR3 disruptions were made by transplacement of the diploid YNN402. For RNR1, YNN402 cells were transformed with the 3.6-kb EcoRI fragment from pNN446 containing the $r n r 1$ : URA3 disruption, and Ura prototrophs were selected, creating YNN403. For the RNR3 disruptions, YNN402 cells were transformed with the $6.7-\mathrm{kb}$ SacI-XhoI fragment from pNN447 containing the rnr3: TRP1 disruption, and Trp prototrophs were selected, creating YNN404. Construction of the sectoring shuffle reporter strain was accomplished by introducing the plasmid pNN448 into YNN405 by transformation and selecting for His prototrophy, creating YNN406. The chromosomal copy of RNR1 was then disrupted by transforming YNN406 with the 3.6-kb EcoRI fragment from pNN446 containing the mnr1:: URA3 disruption and selecting for Ura prototrophy, creating YNN407. Transformants were streaked for single colonies on complete minimal media with $0.2 \times$ adenine for the determination of sectoring ability. Transplacements that disrupted the plasmid copy of RNR1 could lose the HIS 3 URA3 SUP11 plasmid in the absence of nutritional selection and would appear sectored. However, transplacement events that disrupted the chromosomal copy of RNR1 would not produce red sectors because the SUP11 gene is linked to the only viable copy of RNR1 on the plasmid, and every plasmid loss event that would produce red sectors leads to cell death. Transformants that appeared homogeneously white on this media were chosen for further study. They were tested for growth on YP glycerol plates to eliminate petite mutants, which also appear homogeneously white. None of the transformants tested were petite mutants. Several strains were analyzed by Southern analysis and shown to have disrupted the chromosomal RNR1 gene, and one was chosen for further analysis. This strain, YNN407, was then transformed with pNN449 (RNR3 TRP1 $2 \mu \mathrm{m}$ ) by selecting for Trp prototrophy. The resulting strain, YNN408, was tested for sectoring ability on minimal glucose medium supplemented with histidine, lysine, and $0.2 \times$ adenine. It was capable of losing pNN448 and producing sectors, as shown in Figure 3. A red colony that had lost pNN448 was isolated, YNN409, and shown by Southern analysis to have lost the functional RNR1 allele linked to the plasmid.

\section{DNA blot and RNA blot analysis}

DNA was labeled by the hexamer primer method (Feinberg and Vogelstein 1983). Hybridizations for Southern blots were carried out, as described previously (Elledge and Davis 1987). RNA was resolved on formaldehyde-1\% agarose gels (Maniatis et al. 1982), and hybridizations were carried out as described for the Southern analysis above.

\section{Induction of RNR expression of 4-NQO}

SK46 cells were grown to mid-log phase in YPD. 4-NQO was added to a final concentration of $0.25 \mu \mathrm{g} / \mathrm{ml}$. Aliquots of cells were taken at 30-min intervals for RNA preparation and analysis. Probes for the RNA blot were the 1.0-kb HindIII-SmaI fragment of $U R A 3$, the $1.7-\mathrm{kb} B g / \mathrm{II}-E c o \mathrm{RI}$ fragment of RNR1, and the $1.1-\mathrm{kb}$ BamHI-EcoRI fragment of RNR3.

\section{$H U$ and MMS induction during cell-cycle arrest}

The strain RC634 was examined to determine whether the stage of the cell-cycle affects the DNA damage induction of the $R N R$ genes. RC634 contains the sst1 mutation that eliminates a protease that normally degrades $\alpha$-factor. Consequently this strain is much more sensitive to the presence of $\alpha$-factor. Yeast $\alpha$-factor causes the arrest of MATa cells at the $\mathrm{G}_{1}$ stage of the cell cycle (Bucking-Throm et al. 1973). We grew RC634 in YPD to $\mathrm{OD}_{600}$ of 0.3 and then added $\alpha$-factor directly to the media at a concentration of $10 \mu \mathrm{M}$. After $2.5 \mathrm{hr}$, these cells were monitored for schmooing, the characteristic elongated morphology that indicates the $\alpha$-factor commitment to mating. Greater than $99 \%$ of the cells exhibited such morphology at this point. 
Then, either HU was added to a final concentration of $100 \mathrm{mM}$ or MMS was added to a final concentration of $0.01 \%$ ( $\mathrm{vol} / \mathrm{vol}$ ), and cells were incubated for an additional $4 \mathrm{hr}$. Cells that were not exposed to $\alpha$-factor were also treated with HU or MMS as cycling controls. Cells treated with $\alpha$-factor but not HU or MMS were monitored after $4 \mathrm{hr}$ for the appearance of buds. Although they maintained a rather exaggerated elongated morphology, $99 \%$ of the cells remained unbudded. After $4 \mathrm{hr}$, cells were harvested, and RNA was prepared for Northern analysis as described previously (Elledge and Davis 1987). The probes for the RNA blot were the internal HindIII-SmaI fragment of $U R A 3$, the 1.7-kb BgIII-EcoRI fragment of RNR1, and the 1.1$\mathrm{kb} B a m \mathrm{HI}-E c o \mathrm{RI}$ fragment of RNR3.

\section{Cell-cycle synchronization}

To determine whether the RNR1 and RNR2 transcripts were regulated by the cell cycle, $L N 114$ was grown to $\mathrm{OD}_{600}$ of 0.5 in 1 liter of YPD at $\mathrm{pH} 3.9$ (correct $\mathrm{pH}$ was achieved with $\mathrm{HCl}$ ) and $\alpha$-factor was added to a final concentration of $1.6 \mu \mathrm{g} / \mathrm{ml}$. Cells were allowed to synchronize for $1 \mathrm{hr}$, at which time an additional $0.8 \mu \mathrm{g} / \mathrm{ml}$ of $\alpha$-factor was added. When $\sim 90 \%$ of the cells appeared unbudded, $\sim 2.25 \mathrm{hr}$ from the first $\alpha$-factor addition, cells were spun down and washed twice with YPD of normal $\mathrm{pH}$ and resuspended in $800 \mathrm{ml}$ of YPD. Forty-milliliter aliquots of cells were taken at 10-min time points for RNA preparation and analysis. RNA blots were prepared as described previously. Probes used were the HindIII-SmaI fragment of URA3, the internal EcoRI-SalI fragment of RNR2, the 1.7-kb BgIII-EcoRI fragment of $R N R 1$, and the $3.0-\mathrm{kb}$ SalI fragment of the POL1 gene.

For determination of the dependence of cell-cycle induction of RNR1 message on protein synthesis, cells were blocked in $\mathrm{G}_{1}$ with $\alpha$-factor, as described above, with the exception that cells were initially treated with $2 \mu \mathrm{g} / \mathrm{ml} \alpha$-factor and after $75 \mathrm{~min}$ of incubation, an additional $1 \mu \mathrm{g} / \mathrm{ml}$ was added. When $>95 \%$ schmoos were observed, the culture was split; sample 1 was left untreated, whereas sample 2 was made $100 \mu \mathrm{g} / \mathrm{ml}$ cycloheximide. After $10 \mathrm{~min}$, the cells were spun down, washed twice with and resuspended in YPD for sample 1 and YPD plus 100 $\mu \mathrm{g} / \mathrm{ml}$ cycloheximide for sample 2 . Time points were taken at $0,20,50$, and $80 \mathrm{~min}$ for RNA preparation and analysis.

\section{Acknowledgments}

We thank W. Harper and D. Allis for critical comments on the manuscript; L. Thelander and D. Martin for plasmids, B. Fuller for strains, and W. Shanabruch and A. Sachs for helpful discussions. We also thank K. McEntee and Kevin Yagle for communicating unpublished results. S.J.E. was a Helen Hay Whitney Fellow and an American Cancer Society Senior Fellow during the course of this work. This work was supported by grant 5R37-GM21891 and National Institutes of Health grant AGO2908 to R.W.D.

\section{References}

Albert, D.A. and E. Nodzenski. 1989. M2 subunit of ribonucleotide reductase is a target of cyclic AMP-dependent protein kinase. I. Cell. Physiol. 138: 129-136.

Andrews, B.J. and I. Herskowitz. 1989. Identification of a DNAbinding factor involved in cell cycle control of the yeast HO gene. Cell 57: 21-29.

Barker, D.G., J.M. White, and L.H. Johnston. 1985. The nucleotide sequence of the DNA ligase gene (CDC 9) from Saccharomyces cerevisiae: A gene which is cell-cycle regulated and induced in response to DNA damage. Nucleic Acids Res. 13: $8323-8337$.

Benton, W.D. and R.W. Davis. 1977. Screening $\lambda$ gt recombinant clones by hybridization to recombinant clones in situ. Science 196: $180-183$.

Bucking-Throm, E., W. Duntze, L.H. Hartwell, and T. Manney. 1973. Reversible arrest of haploid yeast cells at the initiation of DNA synthesis by a diffusible sex factor. Exp. Cell Res. 76: $99-110$.

Burns, V.W. 1956. X-ray induced division delay of individual yeast cell. Radiat. Res. 4: 394-412.

Caras, I.W., B.B. Levinson, M. Fabry, S.R. Williams, and D.W. Martin. 1985. Cloned mouse ribonucleotide reductase subunit $\mathrm{Ml}$ cDNA reveals amino acid sequence homology with Escherichia coli and herpesvirus ribonucleotide reductase. $/$. Biol. Chem. 260: 7015-7022.

Courchesne, W.E., R. Kunisawa, and J. Thorner. 1989. A putative protein kinase overcomes pheromone-induced arrest of cell cycling in S. cerevisiae. Cell 58: 1107-1119.

Cross, F.R. 1988. DAF1, a mutant gene affecting size control, phermone arrest, and cell cycle kinetics of Saccharomyces cerevisiae. Mol. Cell. Biol. 8: 4675-4684.

Elledge, S.J. and R.W. Davis. 1987. Identification and isolation of the gene encoding the small subunit of ribonucleotide reductase from Saccharomyces cerevisiae: A DNA damage-inducible gene required for mitotic viability. Mol. Cell. Biol. 7: 2783-2793.

- 1988. A family of versatile centromeric vectors designed for use in the sectoring-shuffle mutagenesis assay in Saccharomyces cerevisiae. Gene 70: 303-312.

- 1989 a. DNA-damage induction of ribonucleotide reductase. Mol. Cell. Biol. 9: 4932-4940.

1989b. Identification of a damage regulatory element of RNR2, and evidence that four distinct proteins bind to it. Mol. Cell. Biol. 9: 5373-5386.

Engstrom, Y., S. Eriksson, I. Jildvik, S. Skog, L. Thelander, and B. Tribukait. 1985. Cell cycle-dependent expression of mammalian ribonucleotide reductase. I. Biol. Chem. 260: $9114-9116$.

Evans, T., E.T. Rosenthal, J. Toungblom, D. Distel, and T. Hunt. 1983. Cyclin: A protein specified by maternal mRNA in sea urchin eggs that is destroyed at each cleavage division. Cell 33: 389-396.

Feinberg, A.P., and B. Vogelstein. 1983. A technique for radiolabeling DNA restriction endonuclease fragments to high specific activity. Anal. Biochem. 132: 6-13.

Hadwiger, J.A., C. Wittenberg, H.E. Richardson, M. Lopes, and S.I. Reed. 1989. A family of cyclin homologs that control the $\mathrm{G}_{1}$ phase in yeast. Proc. Natl. Acad. Sci. 86: 6255-6259.

Hereford, L. and L.H. Hartwell. 1974. Sequential gene function in the initiation of Saccharomyces cerevisiae DNA synthesis. J. Mol. Biol. 84: 445-461.

Hereford, L.M., M.A. Osley, J.R. Ludwig, and C.S. McGlaughlin. 1981. Cell-cycle regulation of yeast histone mRNA. Cell 24: 367-375.

Hurd, H. and J. Roberts. 1989. Upstream regulatory sequences of the yeast RNR2 gene include a repression sequence and an activation site that binds the RAP1 protein. Mol. Cell. Biol. 9: 5361-5372.

Hurd, H., C.W. Roberts, and J.W. Roberts. 1987. Identification of the gene for the yeast ribonucleotide reductase small subunit and its inducibility by methyl methanesulfonate. Mol. Cell. Biol. 7: 3673-3677.

Johnston, L.H., J.H.M. White, A.L. Johnson, G. Lucchini, and P. Pleviani. 1987. The yeast DNA polymerase I transcript is regulated in both the mitotic cell cycle and in meiosis and is 
also induced after DNA damage. Nucleic Acids Res. 15: $5017-5030$.

Kupiec, M. and G. Simchen. 1986. Regulation of the RAD6 gene of Saccharomyces cerevisiae in the mitotic cell cycle and in meiosis. Mol. Gen. Genet. 203: 538-543.

Lammers, M. and H. Follman. 1984. Deoxyribonucleotide biosynthesis in yeast. Eur. I. Biochem. 140: 281-287.

Lowden, M. and E. Vitols. 1973. Ribonucleotide reductase activity during the cell cycle of Saccharomyces cerevisiae. Arch. Biochem. Biophys. 158: 177-184.

Maniatis, T., E.F. Fritsch, and E.F. Sambrook. 1982. Molecular cloning: A laboratory manual. Cold Spring Harbor Laboratory Press, Cold Spring Harbor, New York.

Mann, G.J., E.A. Musgrove, R.M. Fox, and L. Thelander. 1988. Ribonucleotide reductase M1 subunit in cellular proliferation, quiescence, and differentiation. Cancer Res. 48: 51515156.

McIntosh, E.M., R.W. Ord, and R.K. Storms. 1988. Transcriptional regulation of the cell cycle-dependent thymidylate synthesis gene of Saccharomyces cerevisiae. Mol. Cell. Biol. 8: 4616-4624.

Nash, R., J. Tokiwa, S. Anand, K. Erikson, and B. Futcher. 1988. The Whil gene of Saccharomyces cerevisiae tethers cell division to cell size and is a cyclin homolog. EMBO $J$. 7: 4335-4346.

Nasmyth, K. 1985. A repetitive DNA sequence that confers cell-cycle START (CDC28)-dependent transcription of the HO gene. Cell 42: 225-235.

- 1987. The determination of mother cell-specific mating type switching in yeast by a specific regulator of $\mathrm{HO}$ transcription. $E M B O$ I. 6: 243-248.

Osley, M.A. and D. Lycans. 1987. trans-acting regulatory mutations that alter transcription of Saccharomyces cerevisiae histone genes. Mol. Cell. Biol. 7: 4204-4210.

Osley, M.A., J. Gould, S. Kim, M. Kane, and L. Hereford. 1986. Identification of sequences in a yeast histone promoter involved in periodic transcription. Cell 45: 537-544.

Peterson, T.A., L. Prakash, S. Prakash, M.A. Osley, and S.I. Reed. 1985. Regulation of CDC9, the Saccharomyces cerevisiae gene that encodes DNA ligase. Mol. Cell. Biol. 5: $226-235$.

Pringle, J.R. and L.H. Hartwell. 1981. The Saccharomyces cerevisiae cell cycle. In The molecular biology of the yeast Saccharomyces cerevisiae. Life cycle and inheritance. (ed. J.N. Strathern, E.W. Jones, and J.R. Broach), pp. 97-142. Cold Spring Harbor Laboratory Press, Cold Spring Harbor, New York.

Rothstein, R. 1983. One-step gene disruption in yeast. Methods Enzymol. 101: 202-211.

Ruby, S.W. and J.W. Szostack. 1985. Specific Saccharomyces cerevisiae genes are expressed in response to DNA-damaging agents. Mol. Cell. Biol. 5: 75-84.

Russel, M., S. Kidd, and M.R. Kelly. 1986. An improved filamentous helper phage for generating single-stranded plasmid DNA. Gene 45: 333-338.

Sanger, F., F. Nicklen, and A.R. Coulson. 1977. DNA sequencing with chain-terminating inhibitors. Proc. Natl. Acad. Sci. 74: 5463-5467.

Schiestl, R.H., P. Reynolds, S. Prakash, and L. Prakash. 1989. Cloning and sequence analysis of the Saccharomyces cerevisiae $R A D 9$ gene and further evidence that its product is required for cell cycle arrest induced by DNA damage. Mol. Cell. Biol. 9: 1882-1896.

Schumperli, D. 1986. Cell-cycle regulation of histone gene expression. Cell 45: 471-472.

Sherman, F., G.R. Fink, and C.W. Lawrence. 1979. Methods in yeast genetics. Cold Spring Harbor Laboratory Press, Cold Spring Harbor, New York.

Slater, M.L. 1973. Effect of reversible inhibition of deoxyribonucleic acid synthesis on the yeast cell cycle. /. Bacteriol. 113: $263-270$

Storms, R.K., R.W. Ord, M.T. Greenwood, B. Mirdamadi, F.K. $\mathrm{Chu}$, and M. Belfort. 1984. Cell-cycle dependent expression of thymidylate synthase in Saccharomyces cerevisiae. Mol. Cell. Biol. 4: 2858-2864.

Thelander, L. and P. Berg. 1986. Isolation and characterization of expressible cDNA clones encoding the M1 and M2 subunits of mouse ribonucleotide reductase. Mol. Cell. Biol. 6: $3433-3442$

Weinert, T.A. and L.H. Hartwell. 1988. The RAD9 gene controls the cell cycle response to DNA damage in Saccharomyces cerevisiae. Science 241: 317-322.

- 1989. Controls that ensure the order of cell cycle events. Science 246: 629-634.

White, J., S.R. Green, D.G. Barker, L.B. Dumas, and L.H. Johnston. 1988. The CDC8 transcript is cell cycle regulated in yeast and is expressed coordinately with CDC9 and CDC21 at a point preceding histone transcription. Exp. Cell Res. 171: $223-231$

Zagursky, R.J. and M.L. Berman. 1984. Cloning vectors that yield high levels of single-stranded DNA for rapid sequencing. Gene 27: 183-191. 


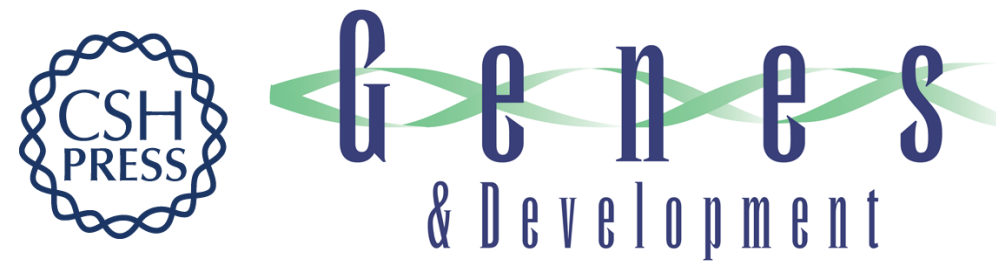

\section{Two genes differentially regulated in the cell cycle and by DNA-damaging agents encode alternative regulatory subunits of ribonucleotide reductase.}

S J Elledge and R W Davis

Genes Dev. 1990, 4:

Access the most recent version at doi:10.1101/gad.4.5.740

References This article cites 46 articles, 21 of which can be accessed free at: http://genesdev.cshlp.org/content/4/5/740.full.html\#ref-list-1

License

Email Alerting Service

Receive free email alerts when new articles cite this article - sign up in the box at the top right corner of the article or click here.

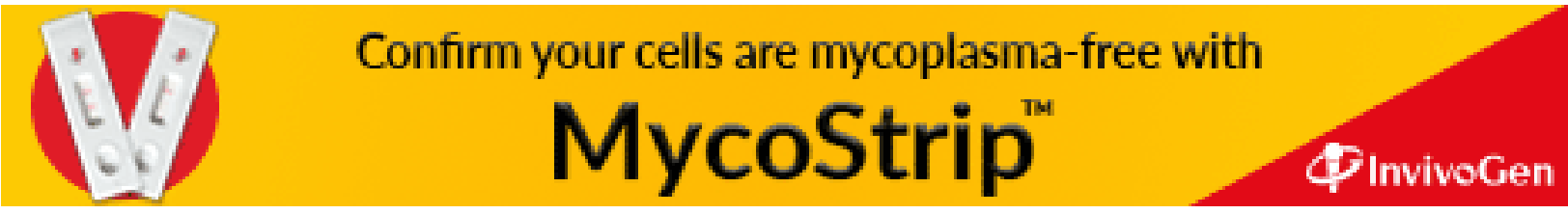

